\title{
Amazonia. Violencias, resistencias, propuestas
}

Amazon. Violence, resistance, proposals

L'Amazonie. Violences, résistances, propositions

\section{Alberto Acosta}

\section{CpenEdition}

\section{Journals}

Edición electrónica

URL: http://journals.openedition.org/rccs/6004

DOI: $10.4000 /$ rccs. 6004

ISSN: 2182-7435

\section{Editor}

Centro de Estudos Sociais da Universidade de Coimbra

\section{Edición impresa}

Fecha de publicación: 1 septiembre 2015

Paginación: 39-62

ISSN: 0254-1106

\section{Referencia electronica}

Alberto Acosta, "Amazonia. Violencias, resistencias, propuestas », Revista Crítica de Ciências Sociais [En línea], 107 | 2015, Puesto en línea el 04 septiembre 2015, consultado el 19 abril 2019. URL : http:// journals.openedition.org/rccs/6004; DOI : 10.4000/rccs.6004 


\section{ALBERTO ACOSTA}

\section{Amazonia. Violencias, resistencias, propuestas}

La Amazonia, ese vasto territorio en América del Sur, alberga sobre todo dos dicotomías, la abundancia y la violencia; se debate permanentemente entre la vida y la muerte. Durante mucho tiempo la inmensa selva amazónica ha sido vista como una reserva de recursos naturales donde el capital hace "sus compras" a conveniencia. La misma complejidad de ese territorio hace necesarias nuevas perspectivas y varias propuestas de salida a su posible devastación. Ese territorio tiene vida propia y es generador de nuevos saberes, esos que el modelo occidental trata de callar; eso explica también porque se ha convertido en un territorio de resistencias. Es urgente pensar en salidas globales y sobre todo locales para los diversos problemas antes de que sea demasiado tarde. Se precisan respuestas integrales que permitan transitar hacia el buen vivir o sumak kawsay y que nos posibiliten pensar en una sociedad posextractiva y poscapitalista. Desmercantilizar la Amazonia es el reto impostergable.

Palabras clave: Amazonia; buen vivir; ecología; (pos)capitalismo; exploración de recursos naturales; resistencia.

Palavras-chave: Amazónia; bom viver; ecologia; exploração de recursos naturais; (pós-) capitalismo; resistência.

Nada es un signo más real de necedad que hacer lo mismo y lo mismo una y otra vez, y esperar que los resultados sean diferentes. Albert EINSTEIN (1879-1955)

¿Qué buscaban los europeos cuando llegaron a América, en concreto a la Amazonía? ¿Qué buscan las transnacionales en la actualidad? ¿Qué pretenden los distintos gobiernos, progresistas o neoliberales?

La Amazonia fue tempranamente incorporada en el proceso de revalorización del capital, es decir en la división internacional del trabajo, que dio origen al capitalismo.

Cristóbal Colón, con su histórico viaje en 1492, sentó las bases de la dominación colonial, con consecuencias indudablemente presentes hasta nuestros días. El genovés buscaba recursos naturales, especialmente 
especerías, sedas, piedras preciosas y sobre todo oro. Colón, quien llegó a mencionar 175 veces en su diario de viaje a este metal precioso, consideraba que "el oro es excelentísimo; del oro se hace tesoro, y con él, quien lo tiene, hace cuanto quiere en el mundo, y llega incluso a llevar las almas al paraíso" (1986: 292).

Su viaje, en consecuencia, abrió necesariamente la puerta a la conquista y la colonización. Con ellas, en nombre del poder imperial y de la fe, empezó una explotación inmisericorde de los recursos naturales. Con la llegada de los europeos a Abya Yala, por efecto, especialmente, del robo y del saqueo, de la sobreexplotación de la mano de obra y del aparecimiento de desconocidas enfermedades en estas tierras, se produjo un masivo genocidio. Esta auténtica hecatombe demográfica se llevó a cabo, en última instancia, en nombre del progreso y de la civilización occidental y cristiana.

Para sostener la producción amenazada por dicho genocidio, se recurrió al violento traslado forzoso de gran cantidad de mano de obra africana esclava. La esclavitud, existente en el mundo desde mucho tiempo atrás, fue un puntal de la colonización europea y permitió el desenvolvimiento global del naciente capitalismo. Fue un importante elemento para el proceso de industrialización al ser una fuerza de trabajo en extremo barata. Esto lo reconocería con claridad Karl Marx:

Sin esclavitud no habría algodón; sin algodón no habría industria moderna. La esclavitud ha dado su valor a las colonias, las colonias han creado el comercio universal, el comercio universal es la condición necesaria de la gran industria. Por tanto, la esclavitud es una categoría económica de la más alta importancia. (1847: cap. 2, par. 1)

Desde esa época, se fraguó un esquema extractivo de exportación de Naturaleza desde las colonias en función de las demandas de acumulación del capital de los países imperiales, los actuales centros del entonces naciente sistema capitalista. Esquema que se mantiene intacto hasta la actualidad.

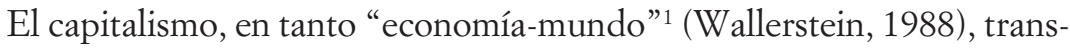
formó a la Naturaleza en una fuente de recursos aparentemente inagotable: pretensión por demás insostenible, tal como lo demuestran los problemas ambientales globales. Ahora, el capitalismo en crisis, demostrando su desprecio por la vida, así como su asombroso y perverso ingenio para buscar y encontrar nuevos espacios de explotación, está colonizando el clima.

\footnotetext{
${ }_{1}$ El "socialismo realmente existente", en verdad, formaba parte de dicha economía-mundo. Nunca logró erigirse como una opción alternativa en términos civilizatorios.
} 
El mecanismo REDD (Reducing Emissions from Deforestation and Forest Degradation) es seguramente el mejor ejemplo actual de la mercantilización de los espacios naturales o la biomasa. En este empeño la Amazonia es una de sus presas más cotizadas para el comercio de la vida.

\section{La Amazonia, periferia de la periferia}

El espíritu inicial de la conquista se plasmó en sucesivos "descubrimientos" de nuevos territorios por su potencial en recursos naturales. Así, el "descubrimiento" económico del Amazonas, se cristalizó en 1640, cuando el padre Cristóbal de Acuña, enviado del rey de España, informó a la corona sobre las riquezas existentes en los territorios "descubiertos" por Francisco de Orellana en 1540. Acuña encontró maderas, cacao, azúcar, tabaco, minas, oro... recursos que aún alientan el accionar de los diversos intereses de acumulación nacional y transnacional en la Amazonia.

Desde aquella época arrancó una larga y sostenida carrera tras de "El Dorado", carrera que aún no concluye... En la etapa republicana las violencias desatadas por la voracidad de la conquista y la colonización no concluyeron. Aumentaron.

El estilo de desarrollo predominante en la Amazonia se basó y se basa aún en extraer recursos naturales. Si bien en muchos casos las tecnologías cambian, se repite un patrón que se remonta a la época colonial: la mayor parte de los recursos son apropiados para ser exportados. En efecto, las principales actividades extractivas incluyen minerales, hidrocarburos, madera, productos agrícolas y ganadería.

La extracción masiva de recursos naturales para la exportación ha sido una constante en la vida económica, social y política de muchos países del Sur global, no se diga en la Amazonia. Y la otra constante es la elevada propensión a importar bienes de fuera de la Amazonia. Este desencuentro entre oferta y demanda amazónicas, derivado de patrones de consumo foráneos, por un lado, y de la inserción sumisa en el mercado mundial como exportadora de materias primas, por otro, explica gran parte de la complejidad económica de esta zona.

Con diversos grados de intensidad, todos los países amazónicos están atravesados por estas prácticas primario exportadoras. Esta dependencia de las metrópolis capitalistas, a través de la extracción y exportación de materias primas, se mantiene prácticamente inalterada hasta la actualidad. Algunos países apenas han cambiado unos cuantos elementos relevantes de la modalidad primario exportadora tradicional, al lograr una mayor intervención del Estado en estas actividades y al conseguir una mayor participación en la renta de dichos productos primarios exportados. Por lo tanto, más allá 
de algunas diferenciaciones más o menos importantes, esta modalidad de acumulación parece estar en la médula de la propuesta productiva tanto de los gobiernos neoliberales como de los gobiernos progresistas. Según Eduardo Gudynas: ${ }^{2}$

En la actualidad la Amazonia estalla en fragmentos. [...] En efecto, algunos sitios amazónicos están directamente ligados a la globalización, generalmente como proveedores de recursos naturales, mientras otras extensas zonas se mantienen al margen de esos procesos, y sus principales relaciones son locales o regionales. El estilo de desarrollo impuesto sobre la Amazonia se basa en una apropiación de los recursos naturales volcados a su utilización fuera de la región, y particularmente su exportación, lo que determina una afectación desigual del territorio. (2007: 2)

Los diversos gobiernos de la región, una y otra vez, vieron en la Amazonia el verde color de los dólares y no el verde de la vida. Y en consecuencia forzaron y siguen forzando las prácticas extractivas.

Además, una y otra vez encontraron en la Amazonia una válvula de escape de los problemas en sus otras regiones densamente pobladas. Así, por ejemplo, en lugar de impulsar verdaderas reformas agrarias en las otras regiones de sus países más pobladas y menos equitativas, abrieron la puerta a una masiva e indiscriminada colonización. En definitiva, hay que entender el extractivismo también como la otra cara de la falta de voluntad política para enfrentar el problema agrario y la redistribución de riqueza. Sigue siendo más fácil extraer los ingresos fiscales del subsuelo, que de los bolsillos de los grupos poderosos.

En este punto hay que señalar que la región amazónica es tratada, en la práctica, como una periferia en todos los países amazónicos, que son a su vez la periferia del sistema político y económico mundial, como acertadamente lo explica Thomas Mitschein (2001). Esta realidad contradice el interés desplegado en el debate internacional sobre la Amazonia, cuando esta región es considerada como el banco genético más importante del mundo o (equivocadamente) como el pulmón de la bumanidad. ${ }^{3}$ El discurso oficial sobre la importancia global de la Amazonia, tan repetido en múltiples foros internacionales, se derrumba ante la realidad de un sistema que al revalorizar sus recursos en función de la acumulación de capital pone en riesgo la

\footnotetext{
2 Ver además los aportes de Gudynas y el autor de estas líneas (2011a y 2011b).

${ }^{3}$ La selva amazónica no provee oxígeno a la atmósfera, lo que hace es contener carbono, si se deforesta ese carbono sería liberado.
} 
vida misma en dicha región. Las tasas internas de retorno del capital, de la actividad petrolera, por ejemplo, son muchísimo más elevadas que la capacidad de recuperación de la Naturaleza, si es que ésta puede recuperarse. La Amazonia, no hay duda, es la periferia de la periferia.

Ejemplos de lo dicho se pueden encontrar en todos los países afluentes del Amazonas. La destrucción de las selvas es cada vez más acelerada. La jungla espesa está siendo transformada a gran velocidad en desiertos de monocultivos o en eriales producto de la masiva deforestación legal e ilegal. Se talan los bosques tropicales para dejar sitio al avance de la frontera agrícola intensiva, con cultivos a gran escala, que en poco tiempo, debido a la fragilidad del suelo, dejan de ser rentables para los grandes capitales.

La Amazonia se mantiene como la frontera viva de la colonización. Ahora, ya no es solo una tierra de expansión para el mercado capitalista tradicional a través de la explotación de los recursos naturales, es una región donde proliferan los mercados ficticios: mercados de carbono o de patentes...

En esa explotación -como anota Eduardo Gudynas (cf. supra)- no se perciben límites, ya que persiste la visión de una región "vacía" y retrasada que debe ser "colonizada". En definitiva, se mantiene vigente el mensaje de Cristóbal de Acuña:

Éste es en suma el nuevo descubrimiento de este gran río, que encerrando en sí grandiosos tesoros, a nadie excluye, mas antes, a todo género de gente convida liberal a que se aproveche de ellos.

Al pobre ofrece sustento; al trabajador, satisfacción de su trabajo; al mercader, empleos; al soldado, ocasiones de valor; al rico, mayores acrecentamientos; al noble, honras; al poderoso, estados; y al mismo rey, un nuevo imperio. (1942: 111)

Los sueños de Cristóbal de Acuña se transformaron en una pesadilla continuada. Las violencias y los crímenes han estado y están a la orden del día. La violación de los derechos de los seres humanos y, en el caso de Ecuador, de los reconocidos Derechos de la Naturaleza, recogidos en la Constitución de 2008, es interminable. Como responsables asoman las potencias coloniales y sus cómplices locales, las empresas transnacionales y muchas empresas nacionales, los gobiernos de la región, los organismos internacionales como el Banco Mundial o el FMI... El pretexto o el alibi de tanta devastación social y ambiental, son el desarrollo y el progreso. Y la matriz de tanto crimen y violencia, el sistema capitalista, un sistema que "vive de sofocar a la vida y al mundo de la vida" (Echeverría, 2007). 


\section{Una larga cadena de violencias y resistencias}

La historia de la incorporación de la Amazonia al mercado mundial está llena de sangre y resistencias. La lista es larga. Los ejemplos son múltiples, diversos... como lo han sido las múltiples formas de explotación, en la que las luchas han estado casi siempre presentes. Por eso en estas pocas páginas apenas podemos recordar algunos pocos hechos aislados, conscientes de que se han escrito muchos volúmenes sobre este tema.

Este recuento, que podría empezar en la colonia, tiene muchos casos destacables en la etapa republicana, con la fiebre extractiva de la quina y del caucho, por ejemplo. Así como no detenernos en la atroz Casa Arana, aquella empresa exportadora de látex que se asentó en los corregimientos de El Encanto y La Chorrera, actual departamento del Amazonas en Colombia. Empresa que nació a principios del siglo Xx, a manos del peruano Julio César Arana, quien consolidó un enclave exportador basado en la esclavitud indígena y que contó con el apoyo del ejército peruano. Esta empresa, que luego se transformaría en la Peruvian Amazon Company, provocaría un verdadero genocidio de los pueblos uitotos, boras, okainas y muinanes (Pineda, 2003).

Demos un salto en el tiempo, ya que no hay el espacio suficiente en este texto para poder abordar una realidad tan compleja como la violencia extractivista en la Amazonía. El conflicto socioambiental de los U'wa, en la Amazonia colombiana, en contra de la compañía Oxy, fue uno de los más notables y conmovedores. En los años noventa del siglo Xx, este grupo indígena amenazó con un suicidio colectivo como sacrificio antes que ceder a las transnacionales petroleras: "preferimos una muerte digna, propia del orgullo de nuestros antepasados que retaron el domino de conquistadores y misioneros" (Citado Uribe, 2005: 46).

Dos ejemplos dramáticos de cómo el mercado de recursos naturales arremete sin freno contra la vida de la gente. Sin embargo, ¿cuántas veces la resistencia fue violenta, como violenta fue la agresión? Bastaría recordar las múltiples respuestas de las comunidades indígenas en contra de los conquistadores, de los colonizadores, de los evangelizadores, de los explotadores... en definitiva, de los invasores. Uno de los casos más recientes y violentos fue el vivido en el año 2009 en Bagua, Perú, que tenía como entretelón explicativo la necesidad de cumplir con los compromisos adquiridos en el Tratado de Libre Comercio con los Estados Unidos, como parte de la expansión neocolonial del neoliberalismo.

En Perú también se registran graves enfrentamientos en el departamento Madre de Dios. Allí la minería informal, especialmente del oro, arrasa con Naturaleza y comunidades. Los altos precios del mineral, sumados a la ausencia de otras opciones de vida digna en el país, así como la ausencia de capacidad de 
regulación o amortiguación de los problemas, alientan presiones que dan paso a una espiral de violencia y criminalidad cada vez más explosiva: destrucción del ecosistema, narcotráfico, trata de personas, etnocidio, despojo violento de tierras, reubicación forzada de las comunidades, marginación...

Lo que sucede en el TIPNIS (Territorio y Parque Nacional Isibore Sécure) en Bolivia es otra de esas expresiones de violencia estatal y de resistencia en contra de un gobierno considerado como progresista. La determinación del Régimen de construir una carretera que atraviese el parque ha desatado una polémica en el país y la reacción de las organizaciones indígenas, que exigen además la consulta a los pueblos indígenas, como está establecida en la Constitución boliviana, como nos recuerda Raúl Prada:

El Territorio Indígena del Parque Nacional Isiboro-Sécure está protegido por leyes y la Constitución, además de ser parque, por lo tanto área protegida, es territorio indígena, y exige el respeto establecido constitucionalmente de los Derechos de las Naciones y Pueblos Indígenas Originarios. Por otra parte el TIPNIS tiene que ver con las Resoluciones de Tiquipaya, con la Primera Conferencia Mundial de los Pueblos sobre el Cambio Climático y los Derechos de la Madre Tierra, las mismas que prohíben la explotación en bosques, así como plantean claramente la defensa de los ecosistemas y los ciclos vitales integrados.

[...] El debate ha puesto en la mesa la dirección del proceso, ¿por dónde va? ¿Desarrollismo o Vivir Bien? ¿Extractivismo o alternativa al desarrollo? Discusiones que deberían estar supuestamente resueltas desde la aprobación de la Constitución; no lo están, pues el gobierno y sectores interesados en promover el nombrado "desarrollo" parecen no comprender los contenidos y los alcances de la Constitución y el sentido del proceso constituyente. (2011)

En otro lugar de la Amazonia, en Ecuador, la resistencia de la comunidad kichwa de Sarayaku, en la provincia de Pastaza, logró impedir la actividad petrolera de la Compañía General de Combustibles (CGC) en el bloque 23. Este fue un gran triunfo de una pequeña comunidad organizada, considerando que la empresa recibía inclusive respaldo militar del Estado. Dicha comunidad, que contó con una activa solidaridad internacional, alcanzó un pronunciamiento favorable de parte de la Comisión Interamericana de Derechos Humanos en julio del año 2004, cuando esta dictó una serie de medidas provisionales a favor del pueblo de Sarayaku. En la primera mitad del año 2007 el Gobierno ecuatoriano por fin aceptó dicha resolución. ${ }^{4}$

\footnotetext{
${ }^{4}$ El ministro de Energía y Minas, Alberto Acosta, autor de estas líneas, aceptó esta resolución de manera oficial.
} 
Sin embargo, poco tiempo después volvieron a aparecer las amenazas sobre Sarayaku. En la renegociación del contrato del bloque 10 entre el Gobierno del presidente Rafael Correa y la empresa AGIP, celebrada en noviembre de 2010, las autoridades entregaron a dicha empresa petrolera una porción del bloque 23 que afecta el territorio de varios pueblos indígenas amazónicos. El territorio de Sarayaku queda también integrado en esta ampliación del bloque 10. Esta redefinición del bloque se hizo, nuevamente, a espaldas de las nacionalidades y pueblos afectados, sin habérseles consultado ni pedido consentimiento pese a la gravedad de los efectos que esa decisión traerá a sus vidas y territorios. Igualmente preocupante es la convocatoria para licitar el bloque Armadillo en donde hay evidencias ciertas de la presencia de pueblos libres en aislamiento voluntario, una situación que prohíbe cualquier tipo de actividad extractivista, tal como dispone la Constitución ecuatoriana de 2008. Y por cierto es lamentable la decisión del Gobierno de Correa de ampliar la frontera petrolera al centro sur de la Amazonia, así como la de abrir la puerta a la megaminería en la misma Amazonia.

Otro caso notable en Ecuador, pero que trasciende sus fronteras, es el que devino en el conocido como el juicio del siglo. Un juicio que se inició en contra de una de las grandes trasnacionales petroleras. Indígenas y campesinos amazónicos ecuatorianos sentaron a la compañía Chevron-Texaco en el banquillo de los acusados. Luego de un largo peregrinar por juzgados estadounidenses y después de que un juez de Nueva York denegó la competencia en el caso, se presentó la demanda ante la Corte Superior de Justicia de Nueva Loja, población amazónica más conocida como Lago Agrio, en recuerdo del lugar de origen de la Texaco: Sour Lake.

En Ecuador, la Texaco -hoy Chevron-Texaco- provocó una severa devastación ambiental durante 28 años. Si bien resulta imposible poner precio a la Naturaleza, pues la vida es inconmensurable, el daño se podría cuantificar en miles de millones de dólares por concepto de derrames, contaminación de pantanos, quema del gas, deforestación, pérdida de biodiversidad, por animales silvestres y domésticos muertos, por materiales utilizados sin pago, por salinización de los ríos, por enfermedades (los casos de cáncer llegan a $31 \%$ cuando el promedio nacional es $12,3 \%$ ), por trabajo mal remunerado. Sobre Texaco pesa también la extinción de pueblos originarios como los Tetete y los Sansahuari, así como los daños económicos, sociales y culturales causados a los indígenas Siona, Secoya, Cofán, Kichua y Waorani, incluyendo a los colonos (Martín et al., 2010).

Un argumento central del juicio radica en los procedimientos y las técnicas para la exploración y explotación petrolera, pues Texaco prefirió utilizar métodos más baratos aunque sean contaminantes. La tecnología utilizada 
era prohibida por ley en Estados Unidos. Con este juicio, que ya cuenta con sentencia en firme, más allá de su desenlace, se sienta un precedente al encausar a una de las petroleras más poderosas del planeta.

Este reclamo constituye una oportunidad para sancionar y frenar la contaminación provocada por la actividad petrolera, que se sostiene por la combinación del poder político con el transnacional sobre un discurso que alienta la explotación del petróleo o de los minerales en supuesto beneficio de los habitantes del país, discurso que sostiene una política de ocultamiento de la realidad, una política de intimidación de quienes se oponen, una política de humillación y olvido para las víctimas... mientras que los dólares obtenidos solo en escasos montos beneficiaron al conjunto de la población, pues en su mayoría fluyen en pocos bolsillos, sobre todo de las poderosas transnacionales. De por sí esta demanda constituye una oportunidad para empezar a sancionar y frenar la contaminación provocada por la actividad extractiva en la Amazonia y en otras partes del mundo.

Las violencias encuentran también explicaciones regionales atadas por cierto al extractivismo. Brasil avanza en su proceso de someter a los países vecinos. Esta tarea es alentada por la "Iniciativa para la Integración de la Infraestructura Regional Sudamericana" (IIRSA), donde participan todos los países amazónicos y que constituye un proyecto para vincular aún más a la Amazonia a las demandas de acumulación del capital global. La demanda exportadora requiere de vías de traslado y salida de los productos amazónicos. Esta propuesta de integración transnacional surgió en medio del neoliberalismo desbocado y se mantiene en la época de los gobiernos progresistas...

Brasil se asegura aportes energéticos importantes de varios de sus vecinos. No solo está el gas de Bolivia. Hay enormes proyectos hidroeléctricos, con multimillonarias inversiones, en marcha en Perú y Bolivia; se producirá electricidad en estos países andinos para alimentar la creciente demanda energética de Brasil, que fuerza su crecimiento a como dé lugar, sin importar la inundación de bosques o de tierra fértil, la deforestación, la eliminación de la fauna... El capitalismo periférico brasilero, un subimperialismo en esencia, traslada los costos de la imposición de su matriz energética a sus vecinos.

Pero eso no significa que dentro de Brasil no se produzcan situaciones dramáticas como las que vive el pueblo Kayapó: un pueblo indígena de la región amazónica de Mato Grosso y Pará en Brasil, expulsado de la gran curva del río Xingu para dar paso a la construcción de una gran represa hidroeléctrica, que inundará una zona más grande que la superficie del canal de Panamá. En el Brasil mismo habría como poner como ejemplo a aquellas 
medidas que, de una u otra manera, alientan la privatización de la Amazonia, que sigue siendo vista como tierra deshabitada, propicia para satisfacer las apetencias del capitalismo global, que de eso se trata en última instancia.

La lista de personas y pueblos que han resistido es igual de larga que los atropellos sufridos. Hay nombres que jamás podríamos olvidar como el de Francisco Alves Mendes Filho, más conocido como Chico Mendes. Un recolector de caucho, sindicalista y activista ambiental brasileño, que fue asesinado por defender la Naturaleza. Luchó de manera pacífica contra la extracción de madera y la expansión de los pastizales sobre el Amazonas. Fundó un sindicato de recolectores de caucho en un intento por preservar sus trabajos y la selva tropical al mismo tiempo. Es enorme la lista de las personas asesinadas por defender la vida, en definitiva víctimas de su activismo en contra de la deforestación, la tala ilegal, del petróleo, de la minería y el aumento de la frontera agrícola y ganadera.

En suma, para los pueblos indígenas de la Amazonia y para las comunidades de colonos, las actividades petroleras, mineras, madereras, colonizadoras, agrarias extensivas: como la soja, la palma africana, la ganadería... ahora los mercados de carbono, en todas sus formas, han significado un cambio radical en su vida. Las comunidades indígenas y los colonos de la Amazonia han sufrido y siguen sufriendo un sinnúmero de atropellos a sus derechos elementales a nombre de un desarrollo y un bienestar que nunca será el suyo.

\section{Iniciativa Yasuní-ITT: una propuesta revolucionaria fraguada en la resistencia}

La idea era simple. No explotar el petróleo en los campos Ishpingo, Tambococha y Tiputini (ITT), que se encuentran en el lado oriental del Parque Nacional Yasuní en la Amazonia ecuatoriana. Esta Iniciativa fue construyéndose poco a poco en la sociedad civil de Ecuador, mucho tiempo antes de que fuera aceptada por el presidente Correa. Esta idea, presentada a nivel gubernamental y públicamente en enero de 2007 por el ministro de Energía y Minas ${ }^{5}$ no tiene gerente-propietario alguno. Era una propuesta de construcción colectiva. ${ }^{6}$ Surgió de la lucha de las comunidades amazónicas indígenas y de colonos en contra de la Texaco, así como de propuestas de vida como las de Sarayaku.

Desde esa realidad, a lo largo del tiempo y nutriéndose de un duro y largo proceso de resistencias en contra de la actividad hidrocarburífera, se fue construyendo la tesis de una moratoria petrolera en el centro sur de la Amazonia ecuatoriana. Esta tesis, formulada en diversos espacios y foros, se plasmó en el año 2000 en el libro escrito por varios autores El Ecuador post-petrolero (Acosta et al., 2000).

\footnotetext{
5 Autor de estas líneas.

${ }^{6}$ Relacionada a esta propuesta hay una amplia bibliografía, se puede consultar a Acosta et al. (2009).
} 
Tres años más tarde, la tesis de la moratoria fue presentada formalmente al Ministerio del Ambiente por parte de varias fundaciones ecologistas. Poco antes, en el año 2001, los grupos que cuestionaban la deuda externa plantearon la posibilidad de un acuerdo histórico con los acreedores internacionales para suspender el servicio de dicho endeudamiento a cambio de conservar la Amazonia; propuesta en línea con el reclamo de la deuda ecológica, en la que los países ricos asoman como los deudores.

Recogiendo todos estos reclamos y estas reflexiones, en junio de 2005, se expuso la propuesta de no explotar el crudo del Yasuní como parte de la tesis de una amplia moratoria petrolera en Un llamado eco-lógico para la conservación, el clima y los derechos, documento de posición de Oilwatch en la primera reunión del grupo especial de expertos sobre áreas protegidas realizada en Montecatini, Italia (Oilwatch, 2005a). Posteriormente se incorporó esta tesis en el libro Asalto al paraíso: empresas petroleras en áreas protegidas (Oilwatch, 2005b).

La Iniciativa Yasuní ITT se basaba en cuatro pilares: 1) conservar una biodiversidad inigualable en todo el planeta -la mayor registrada por científicos hasta el momento-, 2) proteger el territorio y con ello la vida de pueblos indígenas en aislamiento voluntario, 3) cuidar el clima para todo el mundo manteniendo represado en el subsuelo una significativa cantidad de petróleo, evitando la emisión de 410 millones de toneladas de $\mathrm{CO}_{2}, 4$ ) dar un primer paso en Ecuador para una transición pospetrolera y posextractiva, lo que tendría un efecto demostración en otras latitudes. Pero no era todo, como un quinto pilar podríamos asumir la posibilidad de encontrar colectivamente -como humanidad- respuestas concretas a los graves problemas globales derivados de los cambios climáticos provocados por el propio ser humano, exacerbados especialmente en esta última fase de expansión global del capital.

Como contrapartida el Ecuador esperaba la contribución financiera de la comunidad internacional. No se trataba de una vulgar compensación para seguir forzando el desarrollismo (como entendió el Gobierno ecuatoriano). Esta Iniciativa se enmarcaba en la construcción del Buen Vivir o sumak kawsay, que no es una simple propuesta de desarrollo alternativo, sino una alternativa al desarrollo. ${ }^{7}$

Mientras tanto, en el territorio amazónico, en abril de 2013, los pueblos libres cada vez más amenazados por las petroleras, eran diezmados en un terrible enfrentamiento con otra comunidad indígena ya sedentaria.

\footnotetext{
7 Sobre este tema hay una larga lista de trabajos, entre otros se puede consultar los de Albó (2009), Alimonda (2012), Sousa Santos (2010), Houtart (2011), Huanacuni (2010), Kowii (s/f), Oviedo (2011), Prada (2012), Tortosa (2011), Viteri Gualinga (2000).
} 
Motivados por vengar la muerte de una pareja, que fue lanceada meses antes cerca de su casa por un grupo taromenane, con la que mantenían contacto.

A pesar de esta espeluznante historia, que tiene aún capítulos pendientes de esclarecer, el 15 de agosto de 2013, el Gobierno del Ecuador negó a la sociedad ecuatoriana ese tan ansiado tránsito a una sociedad pospetrolera. Aquel día, Rafael Correa, dio por terminada la Iniciativa a pesar de su gran aceptación y de los graves sucesos ocurridos en los territorios amazónicos. El presidente ecuatoriano, no cabe duda, no estuvo a la altura de esta iniciativa revolucionaria.

$\mathrm{Al}$ parecer el negocio petrolero (o minero) no deja de encantar a los gobernantes que desde visiones estrechas no son capaces de reconocer otras fuentes de financiamiento fuera de él. Por lo tanto, para las resistencias, que tienen que darse de la mano con la construcción de alternativas, el camino no es fácil, está plagado de escollos.

El pueblo ecuatoriano -a través de una consulta popular- pretendió asumir la posta luego de que falló el Gobierno del presidente Correa. Y para cristalizarla, un grupo de jóvenes -Colectivo Yasunidos- emprendió la dura tarea de recolectar firmas con el fin de que se convoque a una consulta popular. Los Yasunidos, con muy pocos recursos y sin respaldos efectivos de los grupos políticos establecidos, tuvieron que enfrentar una perversa represión desde varias instancias del Estado. A la postre, esta titánica acción no prosperó por un claro fraude de las autoridades del Consejo Nacional Electoral, las que, en contubernio con el Gobierno, bloquearon la consulta anulando masivamente las firmas presentadas. Para hacerlo esgrimieron una serie de argumentos falaces y también formalidades que contradicen inclusive la propia Constitución. Sin embargo, el hecho de que la Iniciativa Yasuní ITT haya fracasado a nivel gubernamental no quita la opción de construir muchos más Yasuní a lo largo y ancho del planeta, ese es el reto.

\section{¿Conciencia creciente vs capitalismo desbocado?}

En la actualidad, en un ejercicio de mercantilización extrema, del cual no se libran los gobiernos progresistas de América Latina, se convierte cada vez más la capacidad de la Madre Tierra en un negocio para reciclar el carbono.

Al propiciar REDD, en cualquiera de sus versiones, se lleva la conservación de los bosques al terreno de los negocios. Se mercantiliza y privatiza el aire, los árboles y la Tierra misma. Esto amplía la frontera de la colonización del capital. De alguna manera la serpiente capitalista continúa devorando su propia cola.

La creciente mercantilización de la Naturaleza es finalmente un acto de ceguera contrario a la urgencia de iniciar un giro hacia otra civilización. 
Y el comercio, como lo comprendió oportunamente Rosa Luxemburg (1972), sigue siendo una notable fuente de enriquecimiento y acumulación.

En realidad, alentados por la voracidad de acumulación del capital, los mercados de carbono siguen expandiéndose. ${ }^{8}$ Estos mercados adquieren la forma de una burbuja, similar a aquella relacionada con las hipotecas subprime y que llevó al reciente colapso financiero cuyas ondas se expandieron a nivel planetario. La clave de esta "nueva" burbuja es el hecho de que en el centro de los mercados de carbono se encuentra un activo poco claro.

Lo cierto es que el capitalismo, demostrando su asombroso y perverso ingenio para buscar y encontrar nuevos espacios de explotación, está colonizando el clima. La atmósfera es transformada cada vez más en nueva mercancía diseñada, regulada y administrada por los mismos actores que provocaron la crisis climática y que reciben ahora subsidios de los gobiernos con un complejo sistema financiero y político. Recordemos que este proceso de privatización del clima se inició en la época neoliberal impulsado por el Banco Mundial, la Organización Mundial del Comercio y otros tratados complementarios.

La historia de los mercados de carbono arrancó con los esquemas de tope y trueque de contaminación. Los topes o supuestos límites que los gobiernos imponen a las industrias contaminantes, lo hemos visto, lejos de ser una herramienta para reducir la contaminación se han convertido en un estímulo para incluso contaminar más.

Paralelamente se puso en marcha un complejo sistema financiero en el que se estableció el valor de cambio del $\mathrm{CO}_{2}$. Así aparecieron los mercados de carbono, creándose una serie de equivalencias falsas entre las emisiones industriales y la absorción de carbono de los ecosistemas.

En síntesis, la instrumentación de los proyectos REDD, que extienden sus tentáculos por la región amazónica y que están llenos de ambigüedades, no evita la extracción masiva y depredadora de recursos naturales, orientada al mercado capitalista mundial, causante no solo del subdesarrollo, sino también de la crisis ambiental global. Al contrario, estos mercados ambientales podrían actuar, en la práctica, como un incentivo para que las comunidades indígenas o de colonos permitan operaciones extractivas, que de otra manera serían rechazadas en sus territorios. En conclusión, esta remozada lógica mercantil recoge el espíritu de los espejitos con los que los europeos iniciaron la conquista de América.

Lamentablemente la creciente conciencia mundial sobre los problemas ambientales globales y locales no es todavía suficiente para frenar un desbocado capitalismo monopólico generalizado.

${ }^{8}$ Consultar en Lohman (2012). 


\section{No solo una economía pospetrolera, sino otra forma de vida}

Desde la perspectiva crítica de los patrones tradicionales del desarrollo, en la Amazonia, las salidas, con mayor razón, deben ser diversas a las impuestas hasta ahora. Dentro de la Amazonia habrá que construir respuestas en un abanico muy amplio que va desde propuestas para aquellas regiones urbanizadas hasta otras zonas en donde la Naturaleza todavía se mantiene como base de la vida misma. En todos los casos las respuestas deberán surgir del interior de cada una de sus sociedades amazónicas, cuyas potencialidades de acción serán mayores en la medida que se concreten estrategias integracionistas desde lo local, antes que solo esperar respuestas desde el nivel nacional.

Es importante señalar que las visiones y las propuestas del Buen Vivir o Vivir Bien (sumak kawsay o suma qamaña), plasmado en las constituciones de Ecuador (2008) y Bolivia (2009), que no puede ser simplistamente asociado al "bienestar occidental", surgen con fuerza desde la Amazonia (Acosta, 2013).

Lo que interesa aquí es que bajo algunos saberes indígenas amazónicos, no solo andinos, no existe una idea análoga a la de desarrollo, lo que lleva a que en muchos casos se rechace esa idea. Eso no significa negar la posibilidad para que las comunidades amazónicas busquen sus propios caminos para mejorar sus condiciones de vida.

En la visión de las comunidades amazónicas no existe la concepción de un proceso lineal de la vida que establezca un estado anterior y posterior, a saber, de subdesarrollo y desarrollo; dicotomía por la que deben transitar las personas para la consecución del bienestar, como ocurre en el mundo occidental. Tampoco existen conceptos de riqueza y pobreza determinados por la acumulación y la carencia de bienes materiales. El Buen Vivir debe ser asumido como una categoría en permanente construcción y reproducción. En tanto planteamiento holístico, es preciso comprender la diversidad de elementos a los que están condicionadas las acciones humanas que propician el Buen Vivir, como son el conocimiento, los códigos de conducta ética y espiritual en la relación con el entorno, los valores humanos, la visión de futuro, entre otros. El Buen Vivir, en definitiva, constituye una categoría central de la filosofía de la vida de las sociedades indígenas.

Incluso desde círculos de la cultura occidental se levantan voces que podrían estar de alguna manera en sintonía con esta visión indígena, en tanto han comprendido la inviabilidad global del estilo de desarrollo dominante. El Buen Vivir forma parte de una larga búsqueda de alternativas de vida en armonía entre los seres humanos y de estos con la naturaleza, fraguadas al calor de las luchas de la Humanidad por la emancipación y la vida. Por eso mismo los buenos convivires, así, en plural, plantean opciones para que la 
Humanidad pueda escapar con vida de los graves riesgos ecológicos y sociales en ciernes. Muchos de los elementos del Buen Vivir amazónico sirven también de plataforma para discutir y aplicar respuestas -siempre en plural-frente a los devastadores efectos de los cambios climáticos a nivel planetario y las crecientes marginaciones y violencias sociales. En ese sentido, la construcción del Buen Vivir, como parte de procesos profundamente democráticos, puede ser útil para encontrar incluso respuestas globales a los retos que tiene que enfrentar la humanidad.

\section{Algunas ideas gruesas para el qué hacer}

En términos amazónicos, reconociendo la diversidad de situaciones existentes en esta amplia región del mundo, habría que definir algunos aspectos fundamentales para enmarcar la acción. La tarea pasa, en algunos casos, por intentar seriamente la recuperación de la Naturaleza destrozada y en otros habrá que tomar, con urgencia, medidas preventivas para impedir la destrucción ambiental, cultural e inclusive social del resto; como ejemplo de esta aseveración obra la actividad petrolera o minera en la Amazonia que ha destrozado amplias regiones y se apresta a hacerlo en otras.

Adicionalmente, otro tema crucial radica en los polos urbanísticos enquistados en la Amazonia, causantes de enormes destrozos y de presiones productivistas que están minando el equilibrio ecológico de amplias zonas; Manaos, en el corazón de la Amazonia, es quizás el ejemplo más nítido de esta situación.?

Cabe recordar que lo urbano, en este mundo globalizante, ejerce una gran influencia sobre todo lo que le rodea, determina en cierto modo la región circundante porque es lo que mayor dinamismo económico concentra. La mayoría de "ganadores" se concentra en las ciudades y muchos "perdedores" en el desperdigado campo.

Los múltiples conflictos existentes en la región demuestran una situación sin orden alguno, donde prevalecen los intereses particulares, el egoísmo, una lucha feroz por conquistar espacios, la imposición del más fuerte, el clientelismo depredador, la violencia como amenaza y práctica constantes, la explotación irracional y salvaje de la Naturaleza, el desconocimiento de las verdaderas potencialidades amazónicas en términos de biodiversidad y culturas. Aquí, siguiendo a José María Tortosa (2011), se practica la extensión del hobbesianismo maquiavélico, convertido en una especie de geocultura o mentalidad dominante a escala mundial. Ahora ya no es al ateo todo le

\footnotetext{
${ }_{9}^{9}$ Muchas de estas reflexiones están desplegadas en Acosta (2005), aquí se presenta una síntesis actualizada.
} 
estápermitido de Ivan Karamazov. Ahora es, al fuerte todo le está permitido. En ese escenario extendido en toda la región, con diversos grados de intensidad y brutalidad, la vida en y de la Amazonia está en peligro.

La presión GLOBALizante del capital desata dialécticamente fuerzas que impulsan la gLOCALización. Se trata de respuestas que enfocan lo local, desde sus intereses. En contraposición con esta perspectiva de lo local desde la transnacionalización global, urge otra forma de "glocalización" que sintonice lo local con los otros ámbitos de acción estratégica: nacional y regional, sin descuidar el mismo espacio internacional.

Lo real, en estas circunstancias, es que la actual situación es indeseable para la mayoría de la población local. Y que esta está forzada a resistir ante la avalancha que se viene y a aprovechar las potencialidades y capacidades locales disponibles para vivir bien, no puede esperar simplemente a que algún día desde lo nacional se desplieguen políticas justadas a la realidad amazónica o a que la presión internacional interceda efectivamente por la vida en la Amazonia, que es lo que en última instancia está en juego.

Esta necesidad de respuestas locales choca con un grave problema: el escaso conocimiento de la realidad amazónica que se plasma en una amplia gama de limitaciones, entre las que se destacan las siguientes:

- Sobreorientación de la producción hacia fuera de la región.

- Escasa satisfacción de las necesidades básicas con producción local y regional.

- Falta de crédito y asistencia técnica ajustada a la lógica de reproducción de la Naturaleza.

- Patrones de consumo ajenos a la región.

- Predominio de actividades extractivas.

- Modernización agrícola insostenible.

- Expansión de los monocultivos para la exportación y creciente mecanización de las actividades agrarias.

- Monopolización de amplios segmentos de la economía.

- Deforestación masiva del bosque amazónico.

- Escasa e incluso equivocada infraestructura de comunicación (muchas veces es más fácil viajar hacia fuera del región que en su interior).

- Ausencia de adecuados sistemas de información (precios, tecnología, experiencias, entre otros).

- Poco apoyo estatal y desterritorialización del Estado: poco o nula presencia estatal como factor de transformación y mejoramiento de las condiciones de vida, pero si una masiva presencia como factor de represión.

- Existencia de polos de urbanización masiva y una cada vez mayor presión poblacional. 
- Limitadas capacidades para la coordinación y organización colectiva, especialmente en grupos humanos no indígenas.

- Graves distorsiones entre las leyes y normas estatales en relación con reglas no formales de los habitantes amazónicos, especialmente de los indígenas, o incluso incumplimiento abierto de las disposiciones constitucionales que protegen los derechos colectivos, los derechos ambientales y los derechos de la Naturaleza.

En este punto cabe recordar que el objetivo o la misión de todo esfuerzo humano, desde una perspectiva diferente a la dominante en la actualidad, consiste en buscar y crear las condiciones materiales y espirituales para construir y mantener sociedades sustentables. Se precisa un tejido social vigoroso y estrechamente vinculado con una Naturaleza extremadamente diversa.

Con el fin de delinear apenas algunas ideas de acción, hay que reconocer que en esos ámbitos territoriales o locales no hay lugar para grandes teorías. Una realidad tan diversa y rica como la amazónica no puede esconderse detrás de modelos y principios generales, o de complejos agregados estadísticos. Se trata directamente con una gran biodiversidad y con personas y comunidades muy diversas, que son los actores que deberían nutrir el proceso.

Igualmente no conviene ni es posible una reproducción de esquemas nacionales en un ámbito más reducido, sino que hay que diseñar y aplicar un enfoque local del Buen Vivir, estrechamente vinculado con las diversas realidades territoriales: cultura, sabiduría propia y conocimientos adquiridos, patrimonio natural y biodiversidad.

Asumiendo las reflexiones de José María Tortosa (cf. supra), incluso se puede y debe plantear la creación de mini sistemas alternativos fuera del sistema. Una necesidad por lo demás obvia para aquellas comunidades marginadas de la lógica de acumulación y expoliación del capital. Para rechazar el maldesarrollo e incluso el malestar global existente, cabe "intentar crear, a escala local, espacios de relación humana y de satisfacción básica de necesidades dentro de la filosofía del 'bastante', es decir, sin entrar en la lógica capitalista del 'más' o de la acumulación incesante de capital" (Tortosa, 2001: 225). Y desde estas diversas realidades locales habría que intentar constituir redes con el propósito de crear una mayor densidad social alternativa (no confundir con masivos procesos de urbanización). Incluso, mientras no se logra transformar el sistema capitalista, es decir mientras se procesan las transiciones hacia el Buen Vivir, se podría vivir con dignidad aunque sea en sus márgenes.

Entonces, para poder caminar por una senda diferente es preciso superar el objetivo básico y los móviles del modelo occidental de desarrollo y propiciar 
una transformación radical de las concepciones convencionales del desarrollo. A ese respecto, es oportuna la recomendación de Machiavelli (Carta a Guicciardini, 1521) de que ¡ bay que conocer los caminos del infierno, para evitarlos!

En consecuencia, una nueva economía deberá ser repensada desde una visión holística, plasmada en los Derechos Humanos y en los Derechos de la Naturaleza.

Las transiciones, en tanto ruta al Buen Vivir, deben ser pensadas desde las nociones de autocentramiento. Allí, las dimensiones locales quedan muy bien situadas. Esta es una estrategia de organización de la política y de la economía que se construye desde abajo. Solo en la medida en que se han sentado bases sólidas se proyecta progresivamente a niveles regionales e internacionales. Mejor aún si en este empeño se cuenta con el respaldo del gobierno central.

Realizar el autocentramiento, al decir de Jürgen Schuldt (1995), implica decisiones políticas colectivas sobre la "disociación selectiva y temporal del mercado mundial".$^{10}$ Esta disociación-desconexión-ruptura temporales (como se quiera llamar) puede hacerse siguiendo un camino gradual, empezando desde abajo: desde la región o regiones con relación al país y luego del país con respecto al mercado mundial.

El fundamento básico de la vía autocentrada es el desarrollo de las fuerzas productivas endógenas, incluyendo capacidades humanas y recursos productivos locales y el correspondiente control de la acumulación. Todo esto debe venir acompañado de un proceso político de gran participación, de tal manera que se construye "contrapoder" (económico y político) a nivel del país.

Esto implica ir gestando, desde lo local, espacios de poder real, verdaderos contrapoderes de acción democrática en lo político, en lo económico y en lo cultural. A partir de ellos se podrán forjar los embriones de una nueva institucionalidad estatal, de una renovada lógica de mercado y de una nueva convivencia societal. Contrapoderes que servirán de base para la estrategia colectiva que debe construir un proyecto de vida en común: el Buen Vivir, que no podrá ser una visión abstracta que descuide a los actores y a las relaciones presentes, reconociéndolos tal como son hoy y no como queremos que sean mañana.

La propuesta de autocentramiento consiste en reconstruir el vínculo de la economía y política para hacer economía política, tomando como referencias

${ }_{10}$ Sobre este tema, se pueden consultar los trabajos de Schuldt (1995), incluso los escritos conjuntamente con el autor de estas líneas (Schuldt y Acosta, 2000). 
fundamentales el tiempo y el espacio, que han sido violentamente alterados en el capitalismo. Esta propuesta exige el fortalecimiento de los espacios comunitarios.

En resumen, como parte de una gran transformación cultural, precisamos de una visión que supere el fetiche del crecimiento económico, que propicie la desmercantilización de la Naturaleza y los bienes comunes, la descentralización y el cambio de las estructuras de producción y consumo, la redistribución de la riqueza y del poder, como bases para una estrategia de construcción colectiva y constante de otra economía, indispensable para otra civilización. Una economía que tiene que ser repensada desde la propia Amazonía. Es, pues una economía que propenda a la reproducción de la vida y no a la reproducción del capital. Esta tarea implica acciones locales, nacionales como internacionales, que exigen un horizonte utópico de futuro, pero que demandan, por igual, respuestas de corto y mediano plazos.

La transición hacia sociedades posextractivas será sobre bases ecológicas y con creciente equidad social, sobre bases eminentemente democráticas, o no podrá ser. Debemos aceptar que ningún proceso económico puede ser sustentable al margen de los límites que tienen los ecosistemas. Y que la economía es parte de un sistema mayor y finito que es la biosfera. Por lo tanto el crecimiento permanente, como lo dijimos antes, es imposible.

\section{A modo de despedida}

El compromiso con la Amazonia es el compromiso con el mundo, no solo por su peso específico a nivel global, sino porque se trata de un compromiso con una región donde la vida abunda.

No está en juego un mejor sistema de acumulación material. No se trata solo de hacer bien las cosas o de buscar unos cuantos consensos para parchar al sistema. Se precisan cambios profundos, radicales. Urge superar aquellas visiones simplistas que convirtieron al economicismo en el eje de la sociedad. Esta es una apuesta por un futuro diferente, que no se logrará exclusivamente con discursos radicales carentes de propuesta. Sí, otro mundo será posible si se parte de los Derechos Humanos -políticos, económicos, sociales, culturales y ambientales de los individuos y de los pueblos-, así como de los Derechos de la Naturaleza.

El tema sigue siendo político. No podemos esperar la llegada de una solución 'técnica'. Nuestro mundo necesita ser pensando en términos políticos. $\mathrm{Y}$ en consecuencia tenemos que actuar. 


\section{Referencias bibliográficas}

Acosta, Alberto (2005), Desarrollo Glocal - Con la Amazonia en la mira. Quito: Corporación Editora Nacional.

Acosta, Alberto (2013), Buen Vivir - Sumak Kwasay - Una oportunidad para imaginar otros mundos. Barcelona: ICARIA.

Acosta, Alberto; Almeida, Alexandra; Balseca, Milton; Bravo, Elizabeth; Carrión, Fernando; Kimmerling, Judy; Larrea, Carlos; Martínez, Esperanza; Puente, Diego; Ramos, Ivonne; Sosa, Catalina; Viteri, Carlos (2000), El Ecuador post-petrolero. Quito: Oilwatch, Acción Ecológica, ILDIS.

Acosta, Alberto; Gudynas, Eduardo; Martínez, Esperanza; Vogel, Joseph (2009), "Dejar el crudo en tierra o la búsqueda del paraíso perdido. Elementos para una propuesta política y económica para la Iniciativa de no explotación del crudo del ITT" Ambiental.net. Consultada el 28.02.2010, en http://www.ambiental.net/noticias/politicas/AcostaGudynasMartinezVogelITTEc09.pdf.

Acuña, Cristóbal de (1942), Descubrimiento del Amazonas. Buenos Aires: Emecé editores.

Albó, Xavier (2009), "Suma qamaña = el buen convivir", Obets - Revista de Ciencias Sociales, 4, 25-40.

Alimonda, Héctor (2012), "Desarrollo, post-desarrollo y 'buen vivir': reflexiones a partir de la experiencia ecuatoriana", Revista de CLACSO, Crítica y emancipación, $\operatorname{IV}(7), 29-58$.

Colón, Cristobal (1986), Los cuatro viajes - Testamento. Madrid: Alianza Editorial.

Echeverría, Bolívar (2007), "El capitalismo es posible solo sacrificando la Vida", Diario El Comercio, entrevista (agosto 4).

Gudynas, Eduardo (2007), "La nueva geografía amazónica: entre la globalización y el regionalismo", Observatorio del Desarrollo. Montevideo: CLAES, D3E. Consultada el 05.11.2013, en http://ambiental.net/publicaciones/OdelDNueva GeogAmazonia.pdf.

Gudynas, Eduardo; Acosta, Alberto (2011a), "El buen vivir o la disolución de la idea del progreso", in Mariano Rojas (coord.), La medición del progreso y del bienestar - Propuestas desde América Latina. México: Foro Consultivo Científico y Tecnológico de México.

Gudynas, Eduardo; Acosta, Alberto (2011b), "La renovación de la crítica al desarrollo y el buen vivir como alternativa", Utopía y Praxis Latinoamericana, Revista Internacional de Filosofía Iberoamericana y Teoría Social, 16(53), Abril-Junio. Maracaibo: Universidad del Zulia.

Houtart, François (2011), "El concepto del sumak kawsay (Buen Vivir) y su correspondencia con el bien común de la humanidad", Revista Ecuador Debate, 84, Quito: CAAP. Huanacuni Mamani, Fernando (2010), Vivir Bien / Buen Vivir. La Paz: Convenio A. Bello, Instituto Internacional de Investigación, CAOI. 
Kowii, Ariruma (s/f), “El Sumak Kawsay”. Consultada el 11.02.2014, en http://www. uasb.edu.ec/UserFiles/369/File/PDF/CentrodeReferencia/Temasdeanalisis2/ buenvivirysumakkawsay/articulos/Kowii.pdf.

Lohman, Larry (2012), Mercados de carbono - La neoliberalización del clima, serie Debate Constituyente. Quito: Abya-Yala.

Luxemburg, Rosa (1972), Introducción a la economía politica, cuadernos de pasado y presente. México: Siglo XXI Editores.

Martín Beristain, Carlos; Páez Rovira, Darío; Fernández, Itziar (2010), Las Palabras de la selva - Estudio psicosocial del impacto de las explotaciones petroleras de Texaco en las comunidades amazónicas de Ecuador. Bilbao: Hegoa.

Marx, Karl (1847), "Miseria de la filosofía”, Marxists Internet Archive. Consultada el 21.05.2014, en http://www.marxists.org/espanol/m-e/1847/miseria/005.htm.

Mitschein, Thomas (2001), "Os caminhos incertos do desenvolvimento sustentável na Amazonia”, Poematropic, 7, janeiro/junho.

Oilwatch (2005a), "Un llamado eco-lógico para la conservación, el clima y los derechos", Documento de posición Montecatini, Italia. Consultada el 15.03.2014, en http://www.oilwatch.org/galeria/exhibicion/99-campaas/campaa-reas-protegidas/495-un-llamado-eco-lgico-para-la-conservacin-el-clima-y-losderechos.

Oilwatch (2005b), Asalto al paraíso: empresas petroleras en áreas protegidas. Quito: Oilwatch.

Oviedo Freire, Atawallpa (2011), Qué es el sumakawsay - Más allá del socialismo y capitalismo. Quito: Sumak editors.

Pineda, Roberto (2003), "La casa Arana en el Putumayo", Revista Credencial, Historia, 160. Consultada el 18.04.2014, en http://www.banrepcultural.org/node/73209.

Prada Alcoreza, Raúl (2011), "La defensa de los derechos de la Madre Tierra en el TIPNIS”, Bolpress. Consultada el 22.07.2012, en http://www.bolpress.com/art. php?Cod=2011081203.

Prada Alcoreza, Raúl (2012), “Horizontes del vivir bien”. Resumen de la ponencia para LASA 2012. Mimeo.

República de Bolivia (2009), Constitución del Estado Plurinacional de Bolivia.

República del Ecuador (2008), Constitución 2008.

Santos, Boaventura de Sousa (2010), "Refundación del Estado en América Latina - Perspectivas desde una epistemología del Sur", in Alberto Acosta; Esperanza Martínez (orgs.), Soberanias. Quito: Abya Yala, 21-62.

Schuldt, Jürgen (1995), Repensando el desarrollo: Hacia una concepción alternativa para los países andinos. Quito: CAAP.

Schuldt, Jürgen; Acosta, Alberto (2000), “Algunos elementos para repensar el desarrollo - Una lectura para pequeños países”, in Alberto Acosta (org.), El desarrollo en la globalización. Caracas: Editorial Nueva Sociedad, 249-270. 
Tortosa, José María (2001), El juego global - Maldesarrollo y pobreza en el capitalismo global. Barcelona: Icaria.

Tortosa, José María (2011), "Cambios de época en la lógica del 'desarrollo”, Revista Ecuador Debate, 84. Quito: CAAP.

Uribe, Ángela (2005), Petróleo, economía y cultura: el caso U'wa. Bogotá: Siglo del Hombre Editores.

Viteri Gualinga, Carlos (2000), Visión indígena del desarrollo en la Amazonia. Quito: Mimeo.

Wallerstein, Immanuel (1988), El capitalismo histórico. Madrid: Siglo XXI.

Artigo recebido a 20.05.2014

Aprovado para publicação a 07.07.2015

\author{
Alberto Acosta \\ Facultad Latinoamericana de Ciencias Sociales \\ Calle La Pradera E7-174 y Av. Diego de Almagro, Ecuador \\ Contacto: aacosta@flacso.edu.ec
}

\section{Amazon. Violence, resistance, proposals}

The Amazon, that huge South American territory which accommodates two main dichotomies, abundance and violence, is permanently struggling between life and death. For a long time the immense Amazon rainforest was seen as a reserve of natural resources where the capital would go shopping as it pleased. The very complexity of this territory requires new perspectives and alternative proposals to prevent its potential devastation. This territory has a life of its own and generates new knowledge; the very same knowledge the Western model is trying to silence, which also explains why it has become a territory of resistance. It is a matter of urgency to think about global alternatives and, above all, places for the different problems before

\section{L'Amazonie. Violences, résistances, propositions}

L'Amazonie, ce vaste territoire en Amérique du Sud, abrite surtout deux dichotomies, l'abondance et la violence; elle est en conflit permanent entre la vie et la mort. Pendant très longtemps, l'immense forêt vierge amazonienne a été perçue comme une réserve de ressources naturelles où le capital fait "ses emplettes" à son bon plaisir. La complexité même de ce territoire oblige à de nouvelles approches et de nouvelles propositions et initiatives pouvant permettre d'éviter sa dévastation probable. Ce territoire possède une vie qui lui est propre et est générateur de nouveaux savoirs, ceux-là même que le modèle occidental essaie de bâillonner; cela explique aussi pourquoi l'Amazonie est devenue un territoire de résistances. Il est 
it is too late. Comprehensive answers are needed to move towards good living or sumak kawsay, and to enable us to consider a post-extractive and post-capitalist society. Decommodifying the Amazon is the pressing challenge.

Keywords: Amazon; ecology; good living; natural resources exploration; (post-) capitalism; resistance. urgent de penser à des solutions globales et surtout locales aux divers problèmes avant qu'il ne soit trop tard. Il faut apporter des réponses globales qui permettent une transition vers le bien vivre ou sumak kawsay et qui nous permettent d'envisager une société post-extractive et post-capitaliste. Décommercialiser l'Amazonie est un défi incontournable.

Mots-clés: Amazonie; bien vivre; écologie; exploration de ressources naturelles; (post-) capitalisme; résistance. 
